\title{
The loss of potential competition in UK merger control - the emergence of an analytical framework in the CMA's recent decisional practice
}

\author{
Joe Williams* and Stephen Wisking ${ }^{\dagger}$
}

\begin{abstract}
Loss of potential, rather than actual, competition as a theory of harm in merger control has been a hot topic in competition policy debate. The UK's Competition and Markets Authority (CMA) does not face the same jurisdictional constraints that have prevented some of its peer agencies from investigating transactions which give rise to loss of potential competition concerns, and it has adopted a number of recent merger decisions in this area, in many cases after the conclusion of a detailed Phase 2 review. This article outlines the applicable legal framework and explores the CMA's recent decisional practice by reference to three categories of transaction potentially giving rise to a loss of potential competition where the concern is that absent the transaction: (1) one party would have been a market entrant; (2) one or both parties would have become a greater competitive constraint on the other; and/or (3) there was an alternative purchaser which would have made the target more competitive. It then summarizes the CMA's approach to assessing such transactions, including its intention, ability and incentive framework. It concludes by setting out the case for revision to the CMA's Merger Assessment Guidelines to reflect explicitly its approach to these types of transactions.
\end{abstract}

Keywords: UK merger control, Competition and Markets Authority (CMA), theories of harm, loss of potential competition, CMA Merger Assessment Guidelines, killer acquisitions, substantial lessening of competition (SLC) test

\section{Introduction}

Loss of potential, rather than actual, competition as a theory of harm in merger control has been a hot topic in competition policy debate. This arises where the loss of the existing competition between merger parties does not of itself give rise to harm to competition (in the UK, to a 'substantial lessening of competition' (SLC)), but where it is sufficiently foreseeable that, absent the transaction, the competitive position of one or both of the parties would have changed (e.g. through entry into a new market or enhancement of its existing offering) so that the transaction eliminated the potential future competitive overlap between them.

The policy debate in Europe has often focussed on whether merger control even captures such cases and whether amendments are required to jurisdictional tests. ${ }^{1}$ This is particularly the case where the requirements for both parties to generate turnover above particular thresholds may not capture transactions involving smaller targets that may have a competitive significance greater than their current turnover might imply. ${ }^{2}$ However, the UK merger control regime utilizes more flexible jurisdictional tests than many other regimes, particularly those in the EU. For example, the acquisition of 'material influence ${ }^{3}$ is sufficient to bring a transaction within the scope of the UK regime, meaning that minority investments can be caught, and the 'share of supply test' can capture transactions irrespective of the turnover of the parties (and has been applied to cases where one party generates no turnover in the UK). This means

Senior Associate, Herbert Smith Freehills LLP, London.

Partner, Herbert Smith Freehills LLP, London.

The views expressed in this article are personal and do not necessarily reflect the views of Herbert Smith Freehills LLP or any of its clients.

1 See, e.g. the European Commission note of 25 May 2020 in respect of the OECD Roundtable on 'Start-ups, killer acquisitions and merger control',

available at: https://one.oecd.org/document/DAF/COMP/WD(2020)24/ en/pdf (accessed 30 August 2020).

2 i.e. so called 'killer acquisitions', discussed further below.

3 Enterprise Act 2002 (EA 2002), s 26(3).

4 EA 2002, s 23(2A). 
that the Competition and Markets Authority (CMA) has not faced the same constraints which may be faced by its peers when investigating transactions concerning the loss of potential competition. Indeed, the CMA has made use of such jurisdictional tools to investigate the loss of potential competition in a number of recent transactions.

This article considers the CMA's approach to transactions giving rise to a loss of potential competition. Section 2 outlines the relevant legal framework. Section 3 considers the assessment of the loss of potential competition in the CMA's recent decisions by reference to three theories of harm, namely whether absent the transaction:

- one party would have entered the market in competition with the other;

- one or both parties would have become a greater competitive constraint on the other absent the transaction; and

- there was an alternative purchaser which would have made the target a more effective competitor.

Section 4 seeks to identify the key principles underlying the CMA's analytical approach in these decisions, and Section 5 concludes, outlining why there would be value in updated guidance from the CMA.

\section{Legal framework}

\subsection{The SLC test and the evidential threshold}

At Phase 1 the CMA must decide whether it is or may be the case' that a transaction 'may be expected to result in [an SLC]'. ${ }^{5}$ The Courts have held that this bar is a low one. As long as the CMA is satisfied that there is a 'more than fanciful' likelihood of an SLC arising, then the Phase 1 test is satisfied. ${ }^{6}$ The CMA's belief must be 'objectively justified by relevant facts'. ${ }^{7}$

At Phase 2, the CMA must determine whether the transaction 'has or may be expected' to result in an SLC. ${ }^{8}$ In practice, the CMA must find that an SLC has arisen or will arise on the 'balance of probabilities'. ${ }^{9}$ It is not however required to apply a balance of probabilities threshold to each item of evidence it considers. ${ }^{10}$ This point was considered in detail by the Competition

EA 2002, ss 22(1)(b) and 33(1)(b)

6 Office of Fair Trading and Others $v$ IBA Health Limited [2004] EWCA Civ 142, para 48

$7 \quad$ IBA Health (fn 6), para 45.

8 EA 2002, ss 35(1)(b) and 36(1)(b).

9 IBA Health (fn 6), para 46. IBA Health considered a merger which was cleared at Phase 1 and accordingly the Court of Appeal's statement of the standard applicable at Phase 2 was made obiter. However, the Court of Appeal has since adopted the same formulation in the context of a Phase 2 merger in British Sky Broadcasting Group Plc v Competition Commission [2010] EWCA Civ 2, para 42.
Appeal Tribunal (CAT) in British Sky Broadcasting Group plc $v$ Competition Commission. ${ }^{11}$ Central to the Competition Commission's (as the CMA then was) finding that British Sky Broadcasting Group plc (BSkyB) had acquired material influence over ITV plc (ITV) via its acquisition of a $17.9 \%$ stake was that BSkyB would, in practice, be able to block a special resolution of ITV's shareholders, thereby having the ability to veto certain strategic decisions of ITV (such as capital raisings or a takeover by scheme of arrangement). The question before the CAT was whether the Competition Commission (CC) had to reach a decision on the balance of probabilities as to whether or not ITV would absent the transaction have pursued each of the strategic alternatives posited by the CC, or whether it was sufficient for the CC to conclude in the round that, on the balance of probabilities, the transaction gave rise to an SLC, without making specific findings in respect of each the potential strategies. In finding in favour of the $\mathrm{CC}$, the CAT observed that requiring the $\mathrm{CC}$ to 'establish particular future events or courses of events on the balance of probabilities is unrealistic and [...] seeks to introduce a spurious degree of precision into the statutory tests'. ${ }^{12}$ Instead, it must 'give full and proper consideration to the evidence' and then 'ask itself whether it is satisfied on the balance of probabilities that there will be an SLC caused by the transaction'. ${ }^{13}$ The CAT's analysis was cited with approval by the Court of Appeal. ${ }^{14}$

Separate from the question of the standard of proof is the question of the quality of the evidence required for the CMA to satisfy itself that the standard of proof is met. This will depend upon the specific circumstances. The Court of Justice of the European Union (CJEU) in Tetra Laval has emphasized the need for 'great care' where an analysis focuses not on past or current events but instead on predictions of future outcomes, ${ }^{15}$ and requires the identification of 'various chains of cause and effect' and an assessment of which of those are 'most likely' ${ }^{16}$ The CJEU concluded that in such cases:

the quality of the evidence produced by the Commission in order to establish that it is necessary to adopt a decision [prohibiting a transaction] is particularly important, since that

$10 B S k y B$ (fn 9), para 52, endorsing the judgment of the CAT (BSkyB $v$ CC [2008] CAT 25, para 80).

11 Ibid.

$12 B S k y B$ (CAT) (fn 10), para 78.

$13 B S k y B$ (CAT) (fn 10), para 80.

14 BSkyB (Court of Appeal) (fn 9), paras 52-55.

15 Case C-12/03 P Commission of the European Communities v Tetra Laval, ECLI:EU:C:2005:87, para 42.

16 Tetra Laval (fn 15), para 43. 
evidence must support the Commission's conclusion that, if such a decision were not adopted, the economic development envisaged by it would be plausible. ${ }^{17}$

The English courts have drawn a distinction between the circumstances in Tetra Laval, where the future period the European Commission had to examine in order to determine whether conglomerate effects would arise was 'lengthy', with circumstances where merger parties are already competitors. ${ }^{18}$ In $B S k y B$, the Court of Appeal observed that BSkyB and ITV were already 'significant competitors' and the timescales under consideration were not 'lengthy' and therefore it was 'not difficult' to envisage the circumstances under which the transaction would enable BSkyB to exercise material influence over ITV. ${ }^{19}$

\subsection{The counterfactual}

Theories of harm concerning the loss of potential competition are typically predicated on the pre-merger competitive position not being the relevant counterfactual. Instead, for the loss of potential competition to give rise to an SLC, the relevant counterfactual must be more competitive than both the pre-merger and post-merger competitive positions. Indeed, many of the theories of harm outlined below live or die on the counterfactual assessment. For example, in cases where the theory of harm is that absent the transaction the buyer would have entered the relevant market organically, if there is insufficient evidence that such entry would have happened in the counterfactual, then no SLC can arise.

The counterfactual is not a distinct statutory test, but a part of the toolkit used by the CMA in determining whether or not a transaction gives rise to an SLC. ${ }^{20}$ Indeed, in cases requiring a detailed assessment of potential future events (such as loss of potential competition cases), the judgment of the CAT in BSkyB $v$ Competition Commission suggests that the CMA's approach to the counterfactual should be a flexible one, which should remain 'alive, vibrant and important' throughout the CMA's assessment of a transaction. ${ }^{21}$ The CMA is not required to reach a finding on the counterfactual on the balance of probabilities, instead it must identify the 'most likely' counterfactual from the range of potential counterfactuals. ${ }^{22}$

17 Tetra Laval (fn 15), para 44.

$18 B S k y B$ (Court of Appeal) (fn 9), paras 66-67.

$19 B S k y B$ (Court of Appeal) (fn 9), para 67.

$20 B S k y B$ (CAT) (fn 10), para 91.

$21 B S k y B$ (CAT) (fn 10), para 91.

$22 B S k y B$ (CAT) (fn 10), para 92; CMA Merger Assessment Guidelines, September 2010 (CC2), para 4.3.6.

23 Case C-307/18 Generics (UK) Ltd and Others $v$ Competition and Markets Authority, ECLI:EU:C:2020:52.

\subsection{When does potential competition arise?}

This is a question which has been considered recently by the CJEU, in the context of so-called 'pay for delay' agreements in the pharmaceutical sector. ${ }^{23}$ One issue ${ }^{24}$ referred to the CJEU by the CAT was whether the patent holder (in that case GlaxoSmithKline) and the generic pharmaceutical manufacturers were potential competitors in the supply of the drug which was the subject of the agreements in question. Whilst the judgment of the CJEU concerns the application of Article 101 of the Treaty on the Functioning of the European Union, it does set out some general principles regarding the assessment of potential competition which can be read across to merger control.

The CJEU stated that the core question is whether there are 'real and concrete possibilities of [the generic pharmaceutical manufacturers] joining [the relevant] market and competing with one or more of the [patent holders]'. ${ }^{25}$ In particular, it must be determined whether or not such 'real and concrete possibilities' existed absent the agreement in question, which have been lost as a result of the agreement in question. ${ }^{26}$ In this regard, the 'mere wish' of the potential entrant is not sufficient, the evidence must show that it had the ability both to enter, and to retain its place upon entry. ${ }^{27}$ The CJEU then posited two questions which must be answered before it can be concluded that potential competition exists: ${ }^{28}$

- First, does the potential entrant have 'a firm intention and an inherent ability to enter the market'? Central to this question is whether, at the time of the agreement in question, the potential entrant had taken sufficient preparatory steps towards market entry such that it would enter within 'such a period of time as would impose competitive pressure on [the counterparty]'; ${ }^{29}$ and

- Second, whether there are insurmountable barriers to entry which would prevent the potential entrant from entering effectively. This requires an assessment of the particular legal and economic context of the markets in question. ${ }^{30}$

The Court also identified a third question, namely whether there are additional confirmatory factors supporting a finding of potential competition, ${ }^{31}$ for example the expressed intention of the potential entrant to enter

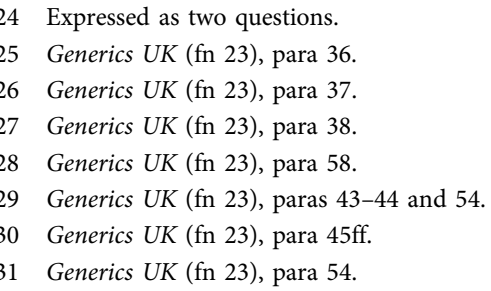

4 Expressed as two questions.

Generics UK (fn 23), para 36.

Generics UK (fn 23), para 58

Generics $U K$ (fn 23), para $45 \mathrm{ff}$

Generics UK (fn 23), para 54 
the market, ${ }^{32}$ or evidence of the patent holder perceiving the potential entrant as a competitive threat. ${ }^{33}$ Evidence of such factors does not appear to be an essential part of the legal test articulated by the CJEU, but instead a cross-check to be applied to ascertain whether there is evidence which buttresses or is inconsistent with the conclusion suggested by the answer to the two questions identified above. $^{34}$

\subsection{Implications for the assessment of the loss of potential competition in merger control}

As regards the application of the SLC test, analysing the loss of potential competition requires a prediction of what the merger parties may (at Phase 1) or were likely (at Phase 2) to have done in the counterfactual over a potentially greater timeframe than in other cases. The existing statutory framework as interpreted by the Courts gives the CMA the flexibility to do this, however, it also emphasizes that the CMA's decision must have a proper factual and evidential foundation (even at Phase 1). The CMA's assessment of future behaviour must therefore be based on existing factual evidence.

Whilst the standard (the balance of probabilities at Phase 2) is no different for loss of potential competition cases, there is a need for better quality evidence in cases where the theory of harm requires an assessment over a longer timeframe where the causal chain between current facts and the posited SLC is less clear. In this regard, potential competition cases exist along a spectrum. In those cases involving parties in significant existing competitive relationships, where the posited events giving rise to the SLC will arise only a short time in the future, the quality of evidence required may be little different from transactions concerning the loss of actual competition giving rise to immediate effects. However, taken together, the judgments of the Court of Appeal in $B S k y B^{35}$ and of the CJEU in Tetra Laval ${ }^{36}$ show that where existing competition between the parties is limited or non-existent, and alleged effects of the transaction arise further in the future, the evidential burden on the CMA in establishing an SLC on the balance of probabilities is much greater.

As regards the counterfactual, a key finding of the CAT in $B S k y B$ was that the CMA's SLC decision (at Phase 2) must meet the balance of probabilities test in the round.

32 Generics UK (fn 23), para 54ff; Opinion of Advocate General Kokott, para 60.

33 Generics UK (fn 23), para 57.

34 See also Case C-591/16 P H. Lundbeck A/S and Lundbeck Ltd v European Commission, ECLI:EU:C:2020:428, Opinion of Advocate General Kokott, paras 37-113, following the approach of the CJEU in Generics UK.

35 See fn 9.
What this requires is context specific. In the case of transactions where the potential competitive harm arises only from the loss of potential competition, the identification of the appropriate counterfactual will take on a heightened importance, and will be a key element in the overall SLC assessment. The CMA's existing guidance appears to envisage this, for example acknowledging that 'when it considers that the choice between two or more scenarios will make a material difference to its assessment, the [CMA] will carry out additional detailed investigation before reaching a conclusion on the appropriate counterfactual'. ${ }^{37}$ By way of example, in a case where the theory of harm is that, absent the transaction, the buyer would have entered a new product market in competition with the target such that an SLC arises due to the loss of this potential competition, a key question is whether or not the buyer would have entered. Whilst the CMA may not have to decide what form that entry would have taken (e.g. organic entry or the acquisition of an alternative target not giving rise to an SLC), a finding that such entry would likely have taken place would be a key part of the overall SLC finding. ${ }^{38}$

Finally, the judgment of the CJEU in Generics UK sets out a number of principles which appear readily capable of being read across to the assessment of the loss of potential competition in merger control, and have been stated by the High Court in England and Wales to reflect generally applicable competition law principles. ${ }^{39}$ First, central to the assessment is whether the potential entrant has the incentive and ability to enter the market. Second, there must be no insurmountable barriers to that entity entering the market. Third, although it is not necessary for the proposed entrant to have the intention to enter the market in question, a factual finding of such intention will support a conclusion (based on the assessment of the entity's incentive and ability) that the entity is a potential competitor.

\section{The assessment of the loss of potential competition in recent CMA decisional practice}

The CMA's Merger Assessment Guidelines envisage two forms of potential competition. The first, referred to as 'actual potential competition' arises where a transaction removes a potential entrant where: (1) entry was likely in

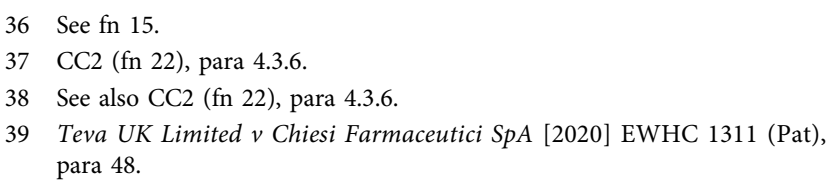


the no-merger counterfactual; and (2) the entry would have led to greater competition. ${ }^{40}$ The second, referred to as 'perceived potential competition' arises where the transaction leads to the loss of an existing competitive constraint which, whilst not present in the relevant market, imposed a competitive constraint because of the threat of entry. ${ }^{41}$ This form of entry does not require a finding that entry is likely to occur.

However, the Guidelines (dating from 2010) do not capture fully the nuances that have arisen in the CMA's recent decisions. The CMA's decisional practice shows that there are at least three different theories of harm which can be used as the lens through which to assess the loss of potential competition, namely: (1) a party is a potential entrant which would constrain the other party; (2) one or both parties would have become a greater competitive constraint; and (3) an alternative purchaser would be a more effective competitor. Each of these is articulated below, along with a brief summary of recent examples of the CMA's decisional practice.

\subsection{A party is a potential entrant which would constrain the other party}

In these cases, the parties are not currently active on the same market (or at least one is not active to any material degree). The no-merger counterfactual is that one party would likely have entered the market leading to the market becoming more competitive, such that the loss of this potential competition constitutes an SLC. In certain circumstances (in particular in the digital and pharmaceutical sectors) such transactions are sometimes pejoratively referred to as 'killer acquisitions', a phrase which is used to describe the scenario where the acquirer, which typically has a significant if not dominant market position, acquires a new or potential entrant which, absent the transaction, would have become a significant competitive force. However, this category encompasses a broader range of scenarios, including where the acquirer is the potential entrant.

\section{a. PayPal/iZettle - omni-channel payment services}

On 12 June 2019, the CMA cleared the completed acquisition by PayPal Holdings, Inc. (PayPal) of iZettle AB (iZettle) (PayPal/iZettle) following a Phase 2 review. ${ }^{42}$ The CMA considered whether the transaction resulted in the elimination of iZettle as a 'potentially significant, nascent competitor' in the market for the supply of omni-channel payment services (i.e. whether the transaction was a 'killer acquisition').

Omni-channel payment services were an emerging form of payment services, involving a single supplier providing integrated offline and online payment services to merchants alongside other services. The CMA considered that the market was at an 'embryonic' stage of development, and assessed the transaction by reference to the supply of omni-channel solutions to smaller merchants in the UK.

Shortly (nine days) before the announcement of the transaction, iZettle had announced an intention to carry out an initial public offering (IPO) which would have given iZettle an estimated market valuation of $\$ 1.1$ billion. PayPal then announced it would acquire iZettle for $\$ 2.2$ billion. The CMA considered whether this valuation meant that 'the acquisition might have been motived by an intention to prevent future competition from an emerging rival'. ${ }^{43}$ However, the CMA was satisfied, following an assessment of PayPal's internal documents and valuation modelling, that the valuation was justified by the synergies including increased sales that PayPal expected to generate, and that the valuation did not suggest any underlying anti-competitive intention in pursuing the transaction. ${ }^{44}$

Having satisfied itself of this, the CMA moved on to assess the competitive effects of the acquisition. PayPal was an established provider of omni-channel payment services, however, iZettle's offering was 'nascent'. Accordingly, the CMA assessed the competitive effects of the transaction by reference to the 'actual potential competition' framework.

- The CMA assessed whether iZettle would have continued with its planned IPO and used the funds raised to enhance its nascent omni-channel offering. The CMA found that there was 'no reason to believe that iZettle would not have proceeded with the IPO absent the merger'. ${ }^{45}$ It found that iZettle's strategy absent the transaction would have been to focus development on its existing services with only limited expansion into online payment services with the result that its omni-channel offering 'would have proceeded and developed only at a slow rate'. ${ }^{46}$

- The CMA noted that although iZettle's expected expansion in the counterfactual would have been limited, the CMA was nonetheless required to assess the

\footnotetext{
40 CC2 (fn 22), paras 5.4.13-5.4.15.

$41 \mathrm{CC} 2$ (fn 22), para 5.4.16.

42 Completed acquisition by PayPal Holdings, Inc. of iZettle AB, CMA Final Report, 12 June 2019

43 PayPal/iZettle (fn 42), para 4.12
}

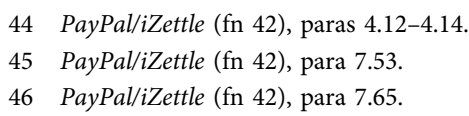


loss of potential competition from that expansion. ${ }^{47}$ The CMA observed that there were a number of other actual or emerging participants in the supply of omni-channel services. ${ }^{48}$ In addition, the limited extent of iZettle's expansion meant that it would be a limited constraint on PayPal even in the counterfactual. ${ }^{49}$ Accordingly, the CMA found that no SLC would arise. ${ }^{50}$

\section{b. Sabre/Farelogix - air travel distribution technology solutions}

On 9 April 2020, the CMA prohibited the anticipated acquisition by Sabre Corporation (Sabre) of Farelogix Inc. (Farelogix) (Sabre/Farelogix). ${ }^{51}$ Whilst a full discussion is beyond the scope of this article, the decision has sparked debate in respect of the approach the CMA took in establishing jurisdiction over the transaction. Farelogix did not generate any turnover in the UK, but the CMA nonetheless found that it was active in the supply of relevant goods or services in the UK for the purposes of the share of supply test and that therefore there was a share of supply increment. The approach taken in this instance shows that the CMA currently considers it has the jurisdictional tools available to target potential competition issues even if one party has virtually no presence in the UK pre-merger. Sabre has appealed the CMA's Decision $^{52}$ and, at the time of writing, it remains to be seen whether the Courts share this view of the CMA's jurisdiction, and what approach this may have on the CMA's future practice in this area.

From a substantive perspective, Sabre/Farelogix involved the examination of the loss of potential competition in two markets. The first was the supply of distribution solutions to airlines (i.e. technology solutions allowing airlines to distribute seats to passengers). The loss of potential competition in merchandising solutions (i.e. technology solutions allowing airlines to offer ancillary services such as extra luggage allowance and other upgrades) is considered in Section 3.2.b. below. Both of these markets are global in scope.

Sabre supplied a Global Distribution System (GDS), a platform used to distribute airline tickets to travel agents for onward sale to passengers. Sabre, alongside the other two main suppliers of GDSs accounted for almost all GDS bookings worldwide. ${ }^{53}$ However, GDSs had technical

7 PayPal/iZettle (fn 42), para 9.16.

48 PayPal/iZettle (fn 42), para 9.29.

49 PayPal/iZettle (fn 42), paras $9.31 \mathrm{ff}$.

50 PayPal/iZettle (fn 42), paras $9.35 \mathrm{ff}$.

51 Anticipated acquisition by Sabre Corporation of Farelogix Inc., CMA Final Report, 9 April 2020.

52 CAT Case 1345/4/12/20 Sabre Corporation v Competition and Markets Authority. limitations and the International Air Transport Association (or IATA), a trade association for airlines, had launched the so-called New Distribution Capability (NDC) standard seeking to address existing limitations. NDC is a computer messaging standard which permits airlines to work directly with travel agents without the need for a GDS (a process referred to as 'GDS bypass'). Farelogix was heavily involved in developing the NDC standard. ${ }^{54}$

The CMA considered that the relevant counterfactual was one in which Sabre would have remained an incumbent GDS supplier and also continued its development of NDC-compatible distribution solutions. ${ }^{55}$ In this scenario, the CMA considered that the evidence showed that Farelogix would continue to compete for NDC distribution solutions. Whilst NDC distribution solutions were only a small part of the market compared to GDS solutions, Farelogix anticipated a 'tipping point' as NDC solutions gained acceptance. Valuation evidence from both parties supported the conclusion that Farelogix would only have grown in significance. ${ }^{56}$

The CMA found that competition amongst the leading GDS suppliers was dampened, an issue exacerbated by the prevalence of single-homing (i.e. selecting only a single GDS supplier) amongst travel agents and the presence of parity clauses limiting GDS suppliers' incentives to compete to attract airlines. ${ }^{57}$ On the other hand, the CMA considered that Farelogix had a greater competitive significance than its small market share would suggest. For example, its entry had led the incumbent GDS suppliers to develop NDC solutions of their own in response. Farelogix was also well placed to benefit from the increased trend toward NDC solutions, given, inter alia, its well developed and high quality NDC offering and its independence, meaning that unlike incumbent GDS suppliers, it did not have to consider the impact on a GDS offering when developing and expanding its NDC offering. ${ }^{58}$

The CMA therefore concluded that the transaction would give rise to an SLC. This transaction is an interesting variant of the 'killer acquisition' theory. It involves not only a small but rapidly growing competitor with competitive impact beyond that suggested by its size, but also market developments being driven by customers (airlines, and indeed their trade association IATA) which

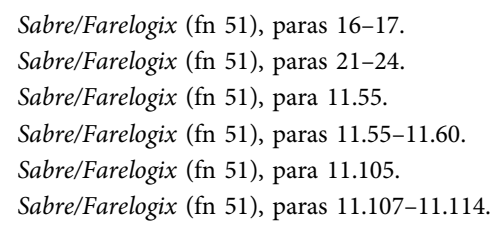


would decrease the significance of the incumbent's primary offering whilst increasing the significance of the target's more nascent offering. The CMA appears to have been particularly concerned about the potential loss of innovation that it considers would have resulted from the transaction.

\section{c. Amazon/Deliveroo - logistics-enabled e-commerce}

On 11 December 2019, the CMA decided that the acquisition by Amazon NV Investment Holdings LLC (Amazon) of a minority stake in Roofoods Ltd (Deliveroo) (Amazon/ Deliveroo) should be referred to a Phase 2 review unless suitable undertakings in lieu could be identified. ${ }^{59} \mathrm{On}$ 4 August 2020, the CMA unconditionally cleared the transaction. ${ }^{60}$ This particular theory of harm (concerning logistics-enabled e-commerce) was not considered at Phase 2 and accordingly the discussion below focusses on the CMA's approach at Phase 1.

The CMA considered whether Deliveroo was a potential competitor in the supply of logistics-enabled ecommerce marketplaces, where Amazon is active through its Marketplace service, allowing third party retailers to make sales to customers and utilize Amazon's logistics network.

In assessing the counterfactual, the CMA noted that there is a consistent trend in the last-mile 'on demand' delivery sector, with companies starting out with a food delivery platform (as Deliveroo did) then expanding into the supply of convenience groceries (as Deliveroo has) and then finally expanding into a wider operation delivering a variety of non-food products (which Deliveroo has not yet done). ${ }^{61}$ The CMA found that this general trend was supported by internal documents and analysts' reports obtained from the parties. ${ }^{62}$ However, as regards Deliveroo specifically, the CMA assessed its internal documents and third party comments, and found that there was no realistic prospect of Deliveroo entering into the supply of logistics-enabled e-commerce services in the foreseeable future. ${ }^{63}$ Having made that finding, the CMA concluded that the transaction did not give rise to a realistic prospect of an SLC in that market. ${ }^{64}$

\section{d. Amazon/Deliveroo - online food delivery platforms}

At Phase 1, the CMA concluded that there was a realistic prospect of an SLC in the market for online food delivery platforms because of the loss of Amazon as a potential entrant in competition with Deliveroo. At Phase 2, the CMA concluded that no SLC arose in this market. ${ }^{65}$

Amazon had previously been active in this market in the UK through its 'Restaurants' offering, but closed that business in November 2018. However, the CMA did not consider that this was determinative of whether Amazon would have re-entered the market in the counterfactual. Instead, the CMA assessed Amazon's incentives, intention and ability to re-enter the market, focussing in particular on an appraisal of Amazon's internal documents. ${ }^{66}$ This assessment led it to the conclusion that Amazon was likely to re-enter the online food delivery platform market in the UK within five years. ${ }^{67}$

In particular, the CMA found that Amazon was focussed on growing its Amazon Prime subscription service, and that it saw a food delivery service as a valuable means of doing so, ${ }^{68}$ and that rolling out fast delivery of restaurant food would also be of benefit to Amazon's wider business, including its convenience grocery business. ${ }^{69}$

The CMA examined Amazon's internal documents regarding the closure of its Amazon Restaurants business, and noted following that closure Amazon almost immediately began considering its investment in Deliveroo, and that this was driven by Amazon's CEO, Jeff Bezos. The CMA therefore found evidence linking the decision to close Amazon Restaurants and to invest in Deliveroo. This led the CMA to conclude that Amazon had a 'strong and continued interest' in online restaurant platforms, and that the UK was an 'important and attractive market' given its large and growing online restaurant platforms market. $^{70}$

The CMA posited that Amazon could achieve re-entry through three main means: (1) organically; (2) acquisition or investment in an existing restaurant platform or adjacent business; or (3) partnership with such business. The CMA found evidence of a range of possible targets, and also that Amazon would be able to overcome potential
59 Anticipated acquisition by Amazon of a minority shareholding and certain rights in Deliveroo, CMA Decision on relevant merger situation and substantial lessening of competition, 11 December 2019.

60 Anticipated acquisition by Amazon of a minority shareholding and certain rights in Deliveroo, CMA Final Report, 4 August 2020.

61 Amazon/Deliveroo (Phase 1) (fn 59), para 72.

62 Amazon/Deliveroo (Phase 1) (fn 59), para 293.

63 Amazon/Deliveroo (Phase 1) (fn 59), para 297.
4 Amazon/Deliveroo (Phase 1) (fn 59), para 298

65 Amazon/Deliveroo (Phase 2) (fn 60), para 7.77

66 Amazon/Deliveroo (Phase 2) (fn 60), paras 6.81ff.

67 Amazon/Deliveroo (Phase 2) (fn 60), paras 6.021-6.203.

68 Amazon/Deliveroo (Phase 2) (fn 60), para 6.112.

69 Amazon/Deliveroo (Phase 2) (fn 60), para 6.124.

70 Amazon/Deliveroo (Phase 2) (fn 60), paras 6.151 and 6.167 
barriers to entry e.g. by utilizing its existing Prime subscriber base and logistics capabilities. The CMA also considered that Amazon could also use its Amazon Restaurants experience to avoid repeating its mistakes and therefore make entry a success. ${ }^{71}$

In its substantive assessment, the CMA focussed on whether the transaction impacted on Amazon's incentives to re-enter the market, given that it was only acquiring a $16 \%$ shareholding. As to the issue of whether Amazon would still enter, the CMA noted that the evidence showed that a restaurant delivery offer was part of Amazon's wider international food strategy, and therefore a single 16\% investment would be unlikely to cause Amazon to revisit this strategy. Notwithstanding some evidence that Deliveroo is Amazon's 'foot in the door' into the UK market, the CMA concluded that there was not sufficient evidence that Amazon acquiring a $16 \%$ stake in Deliveroo would deter its re-entry. ${ }^{72}$

The CMA also considered two theories of harm relating to a potential dampening of competition, one being that Amazon would compete less strongly with Deliveroo post-entry, and the other being that Amazon would use its material influence to discourage Deliveroo from competing against Amazon once Amazon had entered. As to the first, the CMA found that Amazon would not have the incentive to engage in this strategy because it would forgo $100 \%$ of the profits from own account sales in exchange for $16 \%$ of the profit of Deliveroo sales. In addition, any such strategy would be undermined because there would be material diversion to the other players in the market. ${ }^{73}$ As to the second, the CMA found that the influence Amazon could assert over Deliveroo's strategy would not be sufficient to degrade Deliveroo's competitive offer if Deliveroo (or its other shareholders) considered this to be commercially damaging. In addition, the CMA found that such a strategy would again be undermined by competition from third party competitors. ${ }^{74}$

The CMA therefore concluded that no SLC would arise. $^{75}$

\section{e. Takeaway.com/Just Eat - online food delivery platforms}

On 23 April 2020, the CMA cleared the completed acquisition by Takeaway.com N.V. Takeaway.com) of
Just East plc (Just Eat) (Takeaway.com/Just Eat) following a Phase 1 review. ${ }^{76}$

Takeaway.com and Just Eat are both active in the supply of online food platforms, however, their operations did not overlap in the UK. Just Eat was active in the UK, while Takeaway.com formerly was active in the UK but ceased operations there in 2016 .

The CMA examined whether the relevant counterfactual was one in which Takeaway.com re-entered the UK market, either organically or through an alternative transaction. The CMA noted that Takeaway.com had a consistent practice of acquiring established local players rather than entering new geographies organically, and that its stated intention was to do so. It also noted Takeaway.com's former exit from the UK market. It found that these factors in combination were not sufficient for it to conclude that the relevant counterfactual was the pre-merger position. ${ }^{77}$ However, there were two main factors which supported the CMA's ultimate conclusion that there was no realistic prospect that Takeaway.com would have re-entered the UK market absent the transaction, and therefore no realistic prospect of the transaction giving rise to an SLC:

- First, Takeaway.com's internal documents showed it was not actively considering re-entry into the UK market. The CMA found only a single document indicating that the converse may be the case, but considered that there were various factors suggesting that weight should not be placed on it, including its age and lack of detail. By contrast, Takeaway.com's more recent documents showed that the acquisition of Just Eat was consistent with Takeaway.com's overall strategy for global consolidation achieved through acquisitions of local firms with an established market presence. ${ }^{78}$

- Second, the CMA observed that the supply of online food platforms in the UK is characterized by high barriers to entry. Whilst the CMA considered that Takeaway.com could expand its existing logistics network outside of the UK, there were nonetheless two barriers to establishing such a network in the UK which the CMA considered Takeaway.com could not overcome: (1) the lack of existing relationships with UK restaurant chains, with its relationships globally with restaurant chains active in the UK not being sufficient to overcome this; and (2) the lack of an existing consumer-facing business in the UK. ${ }^{79}$
71 Amazon/Deliveroo (Phase 2) (fn 60), para 6.200.

2 Amazon/Deliveroo (Phase 2) (fn 60), paras 7.52-7.53.

Amazon/Deliveroo (Phase 2) (fn 60), paras 7.61-7.62.

Amazon/Deliveroo (Phase 2) (fn 60), paras 7.67-7.69.

Amazon/Deliveroo (Phase 2) (fn 60), para 7.77.
76 Completed acquisition by Takeway.com N.V. of Just Eat plc, CMA Decision on relevant merger situation and substantial lessening of competition, 23 April 2020.

77 Takeaway.com/Just Eat (fn 76), para 29.

78 Takeaway.com/Just Eat (fn 76), para 31.

79 Takeaway.com/Just Eat (fn 76), para 34. 


\section{f. Bauer Media - radio advertising representation services $^{80}$}

On 12 March 2020, following a Phase 2 inquiry, the CMA approved the completed acquisition by Bauer Media Group (Bauer) of four local radio station groups (the Target Stations) (the Bauer Media Merger Inquiry), subject to a behavioural remedy. ${ }^{81}$

The CMA found an SLC in the market for the supply of representation for national advertising to independent radio station groups (representation services). This SLC did not arise as a result of Bauer's acquisition of the Target Stations per se, but because of: (1) Bauer's acquisition of material influence over First Radio Sales Limited (FRS) via the acquisition of a $50 \%$ interest in FRS which was held by UKRD Group Limited (one of the Target Stations); and (2) the fact that the Target Stations represented a large proportion of FRS' customers and Bauer had the ability and incentive to withdraw them from FRS (in favour of self-supply of national representation services) thereby challenging FRS' economic viability.

Bauer was not active in the supply of representation services; ${ }^{82}$ indeed, the CMA found that it had been 'reluctant' to offer such services previously. ${ }^{83}$ The CMA however noted that Bauer had done so historically and may have been 'perceived' as a potential competitor by FRS. ${ }^{84}$ The CMA therefore assessed whether an SLC arose because of the result of the loss of the current constraint Bauer imposed on FRS as a potential competitor, and/or the loss of the increased constraint Bauer would have imposed on FRS in the counterfactual. ${ }^{85}$

In concluding that Bauer was perceived as a constraint prior to the merger, ${ }^{86}$ the CMA noted that Bauer had been approached by a number of third parties seeking representation services, albeit none of these approaches had resulted in an agreement, ${ }^{87}$ and that evidence from FRS showed that FRS viewed Bauer as a constraint, with FRS describing Bauer as 'one of the most likely alternative options' for representation services. ${ }^{88}$

In finding that Bauer would have become a greater constraint following the merger, the CMA assessed: (1) direct evidence of Bauer's future plans; (2) Bauer's ability to provide representation services; and (3) Bauer's incentive to provide representation services. The CMA concluded that Bauer would have entered the market and therefore the loss of FRS as an independent competitor resulted in a 'three to two' merger. ${ }^{89}$

- As to the direct evidence of Bauer's future plans, the CMA found that Bauer's internal documents consistently showed that Bauer was focussed on an acquisition strategy, and that it had refused to provide representation services whilst pursuing this strategy. However, the CMA considered that the relevant counterfactual was the pre-merger situation and therefore these documents were not instructive of what would have happened in the counterfactual (though they gave indications as to Bauer's ability and incentive to supply representation services)..$^{90}$

- As to Bauer's ability, the CMA noted that Bauer had submitted evidence that it would be readily able to provide representation services and that it had not highlighted barriers to doing so. It had also done so previously. The CMA also obtained evidence showing that a significant portion of FRS' existing customer base would be open to representation by Bauer. The CMA therefore found that Bauer faced no significant barriers to entry and would have a sufficient potential customer base to be able to compete. $^{91}$

- In assessing Bauer's incentive, the CMA noted Bauer's evidence that the acquisitions of the Target Stations were aimed at an overall commercial strategy and that, after these acquisitions, providing representation services would support that strategy. The CMA found that, contrary to Bauer's submissions, Bauer would also have had an incentive to offer representation services absent the acquisitions in pursuit of this strategy. The CMA found that in the counterfactual Bauer would still be looking to grow its scale and its primary means of doing so historically (acquisitions and new station launches) would not be sufficient because: (1) absent the acquisition of the Target Stations, there were limited alternative acquisitions available; and (2) launches were limited and took time to translate into a gain of listeners. ${ }^{92}$
80 Herbert Smith Freehills LLP acted for Bauer Media Group on this merger inquiry. The content of this article is based on information in the public domain and does not represent the views of Bauer Media Group.

81 Completed acquisition by Bauer Media Group of certain businesses of Celador Entertainment Limited, Lincs FM Group Limited, Wireless Group Limited, and the entire business of UKRD Group Limited, CMA Final Report, 12 March 2020.

82 Bauer Media Merger Inquiry (fn 81), para 8.12.

83 Bauer Media Merger Inquiry (fn 81), para 8.13. Interestingly, this particular theory of harm was not pursued at Phase 1, and one of the potential SLCs which led to the transactions being referred was a vertical foreclosure theory of harm, premised on Bauer having the incentive to foreclose the independent third party radio stations which previously received representation services from FRS. The CMA found at Phase 2 that Bauer did not have such incentive, see Bauer Media Merger Inquiry (fn 81), Section 11

84 Bauer Media Merger Inquiry (fn 81), para 8.3.

85 Bauer Media Merger Inquiry (fn 81), para 8.4.

86 Bauer Media Merger Inquiry (fn 81), para 8.17.

87 Bauer Media Merger Inquiry (fn 81), paras 8.13-8.14.

88 Bauer Media Merger Inquiry (fn 81), para 8.15.

89 Bauer Media Merger Inquiry (fn 81), para 8.82.

90 Bauer Media Merger Inquiry (fn 81), paras 8.20-8.22.

91 Bauer Media Merger Inquiry (fn 81), paras 8.23-8.27.

92 Bauer Media Merger Inquiry (fn 81), paras 8.28-8.39. 


\subsection{One or both parties would have become a greater competitive constraint}

These cases involve an existing horizontal overlap between the acquirer and the target, the loss of which is not sufficient for an SLC to arise, for example because the parties do not compete closely or because one or other is a weak competitor. However, in the no-merger counterfactual, one or both parties would have improved or altered their competitive position so as to become a greater competitive constraint on the other merger party, and the increase in competitive constraint posed is sufficient for the loss of it to constitute an SLC.

\section{a. PayPal/iZettle - mobile point of sale services}

In PayPal/iZettle, the CMA considered whether an SLC arose in the supply of offline card payment services. iZettle was the leading supplier and whilst PayPal was number two by share of supply, it was not a strong competitor. ${ }^{93}$

The CMA found that PayPal would have invested to improve its competitive position in the supply of offline card payment services in the counterfactual, either through an alternative acquisition or partnership or through improvements to its existing service. ${ }^{94}$

- The CMA found that PayPal had strong incentives to improve its capabilities, based on evidence of its overall strategic aim and the importance of a strong offline payment service in providing attractive omni-channel payment solutions to certain customer groups. The CMA also noted that a 'large part' of the synergies PayPal expected to realize by acquiring iZettle would come from cross-selling iZettle's services to PayPal's existing customer base, leading the CMA to conclude that PayPal saw significant additional revenue potential in an enhanced offline payments product. ${ }^{95}$

- The CMA conducted an assessment of PayPal's internal documents considering alternative assessments or partnerships. The CMA's assessment is heavily redacted, but it led it to conclude that PayPal had a range of strategic options and the resources to pursue them. ${ }^{96}$ The CMA emphasized that it did not need to consider the likelihood of each occurring, but it was satisfied that the most likely no-merger counterfactual was one in which PayPal sought to increase its offline payment capabilities. ${ }^{97}$

The CMA therefore concluded that the relevant counterfactual was one in which PayPal had a substantially improved offline payment services offering. However, it also noted that there was some uncertainty as to the timing and impact of such an improvement given the range of means through which it could be achieved. In particular the CMA noted limitations on what could be achieved in the short term, and couched its conclusion as PayPal being a 'stronger competitor than it currently is, stemming the decline in [PayPal's offline payment services product]'s competitive position'.98

In carrying out its competitive assessment, the CMA therefore assumed PayPal would have a stronger competitive position than currently. Nonetheless, it concluded that the merged entity would face significant competition from a number of existing suppliers, meaning that no SLC would arise even if PayPal were to become a stronger competitive constraint on iZettle than was the case pre-merger. ${ }^{99}$

\section{b. Sabre/Farelogix - merchandising solutions for airline passenger service systems}

To provide services to passengers, airlines use a complex IT infrastructure base known as a Passenger Service System (PSS). Merchandising solutions are built on to airlines' existing PSS services. Sabre supplied PSS services and had a merchandising solution which worked only with its own PSS. Farelogix had a PSS-agnostic solution and was successful in obtaining and retaining customers, and the CMA considered that this would have continued to be the case in the counterfactual. ${ }^{100}$ Further, the CMA considered that, in the counterfactual, Sabre would have had the intention, incentive and ability to develop an NDC compatible PSS-agnostic merchandising solution within three to five years. ${ }^{101}$ This would have made it a closer competitor to Farelogix. The CMA considered this to be the case because: ${ }^{102}$

- Sabre's stated intention was to supply a PSS-agnostic merchandising solution, and it had highlighted the importance of this capability to investors and analysts as part of the rationale for the merger;

- developing enhanced merchandising capabilities would allow Sabre to offset the impact of the value lost from its GDS business as NDC solutions increased in uptake;

- developing a PSS-agnostic solution would offset the impact of losing PSS business to competitors with a stronger merchandising offer; and

- Sabre's internal documents and submissions showed that it had made progress in developing a PSS-agnostic
93 PayPal/iZettle (fn 42), para 33.

94 PayPal/iZettle (fn 42), paras 7.33-7.42.

95 PayPal/iZettle (fn 42), para 7.18.

96 PayPal/iZettle (fn 42), paras 7.33-7.34.

97 PayPal/iZettle (fn 42), para 7.36.
98 PayPal/iZettle (fn 42), para 7.42.

99 PayPal/iZettle (fn 42), s 8.

100 Sabre/Farelogix (fn 51), paras 11.49-11.50.

101 Sabre/Farelogix (fn 51), para 11.48.

102 Sabre/Farelogix (fn 51), paras 11.40-11.48. 
merchandising solution, demonstrating that it had the ability to do so.

In assessing the impact of the merger on the merchandising market, the CMA took account of the improved competitive position it considered Sabre was likely to have in the counterfactual. ${ }^{103}$ The CMA's assessment of the conditions of competition found that, inter alia: Farelogix was the leading supplier of merchandising solutions; whilst there was a third party which would remain a material constraint, Sabre was likely to become the next strongest competitor, with the remaining suppliers offering a more limited constraint; and airlines (i.e. customers) had expressed concerns regarding the impact of the transaction on competition and innovation. Based on these findings, the CMA concluded that the transaction would give rise to an SLC in the merchandising market. ${ }^{104}$

\section{c. Amazon/Deliveroo - online convenience grocery delivery}

In Amazon/Deliveroo, at Phase 1 the CMA found that a realistic prospect of an SLC arose from the combination of Amazon's Amazon Fresh and Amazon Prime Now grocery propositions, and Deliveroo's convenience grocery delivery proposition. ${ }^{105}$ At Phase 2 the CMA concluded that no such SLC arises. ${ }^{106}$

The issue before the CMA is not purely an issue of potential competition; indeed, the CMA noted that at Phase 1 the transaction 'would result in the combination of two of the largest and best established suppliers of online convenience groceries'. ${ }^{107}$

The CMA acknowledged that the parties' current offerings were differentiated, with the principal difference being Amazon's broader product offering, and with delivery speed also being a factor. ${ }^{108}$ However, the CMA considered evidence of the parties' expansion plans and found that they both had incentives to improve their online convenience grocery offers as the market evolves. ${ }^{109}$ The CMA also found that it was possible that Amazon and Deliveroo may become closer competitive constraints on one another compared with other market participants, ${ }^{110}$ although the CMA did not find sufficient evidence that they would have a decisive advantage over other market participants in the medium to long-term. ${ }^{111}$
Against that background, the CMA considered three potential theories of harm in respect of this market:

- First, that Amazon would discourage Deliveroo from competing against it. The CMA concluded that this was unlikely to be the case as Amazon could not exercise sufficient influence over Deliveroo's commercial policy to make Deliveroo act contrary to its own commercial interests, because it was not yet clear whether Deliveroo's expansion plans would make it a closer competitor to Amazon, and because existing market participants would offer a sufficient competitive constraint to counteract this. ${ }^{112}$

- Second, that Amazon would compete less aggressively in the supply of online convenience grocery. This theory was predicated on Amazon being able to raise prices knowing that it would benefit by any reactionary diversion to Deliveroo, whilst simultaneously seeking to protect the profitability of Deliveroo by not competing aggressively. However, the CMA noted that the price effect of such a strategy would be limited because Amazon was only acquiring $16 \%$ of Deliveroo, and the existing competitive constraints in the market would undermine the profitability of this strategy. ${ }^{113}$

- Third, that Amazon would reduce its investment in online convenience grocery delivery and instead rely on Deliveroo for its presence, because it is effectively using the acquisition of $16 \%$ stake in Deliveroo as a stepping stone to a full acquisition. Whilst the CMA found some evidence of this in the internal documents of both Amazon and other Deliveroo shareholders, the CMA also noted that Amazon would have incentives to improve its own service, e.g. by leveraging its re-entry into the online food delivery platforms market and by developing its experience in related markets in the US. The CMA also found that competition in the market would be maintained even if Amazon's incentives to invest were reduced, because its competitors would still be incentivized to invest given online convenience grocery is a 'compelling commercial opportunity.'.14

\subsection{Alternative purchaser as a more effective competitor}

These cases involve an existing horizontal overlap between the acquirer and the target, but with the target being a relatively weak competitive constraint such that no SLC arises as a result of the removal of that constraint. However, the relevant counterfactual is that an alternative purchaser would have acquired the target and would have

\footnotetext{
103 Sabre/Farelogix (fn 51), paras 11.64-11.66. 104 Sabre/Farelogix (fn 51), paras 11.67-11.102. 105 Amazon/Deliveroo (Phase 1) (fn 59), para 288. 106 Amazon/Deliveroo (Phase 2) (fn 60), para 8.322. 107 Amazon/Deliveroo (Phase 1) (fn 59), para 284. 108 Amazon/Deliveroo (Phase 2) (fn 60), paras 8.103-105.
}

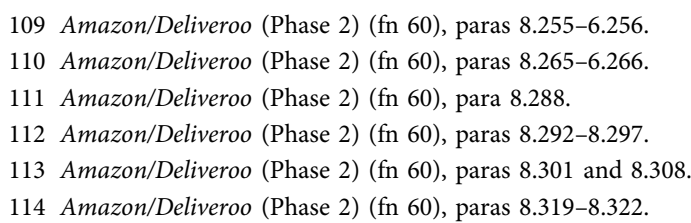

109 Amazon/Deliveroo (Phase 2) (fn 60), paras 8.255-6.256.

110 Amazon/Deliveroo (Phase 2) (fn 60), paras 8.265-6.266.

112 Amazon/Deliveroo (Phase 2) (fn 60), paras 8.292-8.297.

114 Amazon/Deliveroo (Phase 2) (fn 60), paras 8.319-8.322. 
invested, so as to improve the target's competitive position to such a degree that the loss of the competitive constraint that the target would have imposed on the acquirer constitutes an SLC.

\section{a. Bottomline/EPG - electronic payment services}

On 17 March 2020, the CMA cleared the completed acquisition by Bottomline Technologies (de), Inc. (Bottomline) of Experian Limited's (Experian) Experian Payments Gateway business (EPG) (Bottomline/EPG) following a Phase 2 review. ${ }^{115}$

One of the issues explored by the CMA was whether, in the counterfactual, EPG would have been acquired by an alternative purchaser leading to a more competitive outcome. Evidence provided by Experian demonstrated to the CMA that it had taken the strategic decision to sell EPG. ${ }^{116} \mathrm{~A}$ third party whose identity is redacted in the decision (the alternative purchaser) had also bid to acquire EPG before Bottomline was granted exclusivity. The CMA considered the available evidence regarding the alternative purchaser's bid and intentions, and found on the basis of this evidence (which is heavily redacted in the decision) that the most likely counterfactual was that EPG would have been sold to the alternative purchaser. ${ }^{117}$

Having found this to be the case, the CMA then considered what the alternative purchaser's strategy would have been for EPG. The evidence available to the CMA led it to the conclusion that EPG's competitive strategy would have been broadly similar to the pre-merger position if it was acquired by the alternative purchaser, because: (1) there was limited scope for technological development of EPG's software; (2) the alternative purchaser did not appear to have plans to integrate EPG's offering with its own into a bundled, cloud-based software offer, and instead it appeared only to intend to offer EPG's offer alongside its existing offer when explicitly requested by customers; and (3) the alternative purchaser's rationale was to acquire EPG's functionality which was missing from its own portfolio and to acquire EPG's customer base, and it was not intending to pursue a strategy significantly different from that pursued by EPG pre-merger. ${ }^{118}$

The CMA had posited a theory of harm whereby the alternative purchaser would develop EPG's product offering, creating a suite of products which would have meant that competition would have been increased in the counterfactual. However, given its finding that the relevant counterfactual was that EPG's competitive strategy would not change materially under the ownership of the alternative purchaser, it dismissed this theory of harm. ${ }^{119}$

\section{The CMA's approach to assessing the loss of potential competition}

Considering the CMA's recent practice as outlined above in the round, two clear features emerge. The first is the weight it places on internal documents when considering the available evidence, and the second is the (often unarticulated) framework the CMA applies to these cases. This Section seeks to identify the key principles underlying the CMA's approach from its recent practice below.

\subsection{Evidential basis and focus on internal documents}

The CMA consistently places significant weight on merging parties' internal documents in these cases, particularly when seeking to discern what their respective strategies would have been in the no merger counterfactual. This is a consistent feature of the decisions discussed above. More broadly, these decisions reveal that this will be a consistent trend in the CMA's practice going forward, for instance:

- In PayPal/iZettle the CMA remarked that, when carrying out forward-looking assessments (of particular importance in cases concerning the loss of potential competition), the CMA will seek to gather evidence over a number of years. In particular, the CMA noted that 'the internal documents of the Parties and their competitors often set out their respective commercial strategies several years into the future' and that, having reviewed approximately 12,500 documents provided by the parties and by their competitors, the CMA obtained 'insight on how the markets, and those suppliers' offerings, are likely to develop in the future. ${ }^{120}$

- The CMA may be particularly sceptical if there is inconsistency in merging parties' submissions over the course of a transaction, which may lead it to conduct a more thorough analysis of the parties' internal documents so as to ascertain the true positon. In PayPal/iZettle, the CMA observed that PayPal's submissions on the counterfactual had evolved over time and this prompted the CMA to conduct a
115 Completed acquisition by Bottomline Technologies (de), Inc. of Experian Limited's Experian Payments Gateway business and related assets, CMA Final Report, 17 March 2020.

116 Bottomline/EPG (fn 115), paras 6.20-6.34 and 6.46-6.52.

117 Bottomline/EPG (fn 115), paras 6.53-6.65.
118 Bottomline/EPG (fn 115), para 6.84 .

119 Bottomline/EPG (fn 115), paras 8.13-8.15.

120 PayPal/iZettle (fn 42), para 5.9. 
more thorough assessment of PayPal's internal documents and emails. The CMA was critical of PayPal initially omitting from its submissions certain context (regarding PayPal's global strategy) which the CMA considered was relevant to its assessment of the transaction. $^{121}$

- The CMA may place particular weight on documents produced prior to merger discussions, as these offer 'relevant insights into competition between the Parties, competitive conditions generally and future strategic plans of the Parties' which are uncoloured by merger considerations or the expectation that they will be reviewed by the CMA. ${ }^{122}$ The CMA will also scrutinize carefully any differences between documents pre-dating and post-dating the conclusion of the transaction documents. ${ }^{123}$ By extension, it is conceivable that the CMA will, in the case of completed transactions, assess documents pre and post-dating completion, to ascertain whether they reveal evidence regarding the competitive impact of a transaction.

- Put simply, the CMA considers that internal documents are the 'best available evidence' of parties' strategic intentions. ${ }^{124}$

- However, absence of evidence of competitive interaction or monitoring in internal documents may not be conclusive. For example, in its Phase 1 Decision in Amazon/Deliveroo, the CMA considered that its conclusions that the transaction gave rise to a realistic prospect of an SLC were not undermined by a lack of reference in each parties' respective internal documents to the other party, finding that this was 'unsurprising' given the 'nascent' state of the market. ${ }^{125}$

The lesson for merger parties and practitioners is that a thorough diligence exercise in respect of the parties' internal documents is essential when assessing merger control risk in these cases. The CMA may look back over a significant period of time in order to understand how strategic intentions have evolved (e.g. in Sabre/Farelogix it considered internal documents dating from the previous four years $^{126}$ ) and merger parties may therefore need to mirror such an approach in their preparations. In addition, heightened attention to the content of internal documents once a transaction is in contemplation will not be sufficient for merger parties to effectively manage merger control risk. The CMA can be expected to be more sceptical of such documents particularly if they reveal any inconsistencies with earlier documents which can be said to be untainted by the transaction. Accordingly, best practice would now appear to require constant vigilance in

121 PayPal/iZettle (fn 42), paras 7.5-7.7.

122 Sabre/Farelogix (fn 51), para 9.14.

123 Sabre/Farelogix (fn 51), para 9.15.

124 Takeaway.com/Just Eat (fn 76), para 30.

125 Amazon/Deliveroo (Phase 1) (fn 59), para 251.

126 Contrast the two year period specified in question 10 of the CMA's Merger Notice Template. ensuring that internal documents are accurate and consistently reflect the company's true view of its competitive position and the broader competitive landscape.

\subsection{Assessment framework - intention, ability and incentive}

Whilst the CMA sometimes expressly refers to the provisions in its Merger Assessment Guidelines (CC2), ${ }^{127}$ or uses the language of CC2 without citing it, ${ }^{128}$ an approach which is not always explicitly articulated by the CMA emerges from its recent practice. This approach is more nuanced than that described in CC2, and appears to be comprised of four key elements:

- a foundation in existing evidence, sometimes referred to as 'intention';

- the ability, in the counterfactual, of the relevant merging party to change its proposition in the manner theorized, e.g. the ability to expand into a new market;

- the incentive, in the counterfactual, of the relevant merging party to do so; and

- if all of the above show that potential competition is lost as a result of the merger, the impact of the loss of that potential competition.

\section{a. The role of intention}

It was shown in Section 2.3. above that the case law of the CJEU holds that intention is not an essential element when establishing the existence of potential competition, though evidence of it can support a conclusion that potential competition exists. Given that the CJEU judgments cited above reflect generally applicable competition law principles, ${ }^{129}$ the authors consider that these judgments are equally instructive to the domestic UK regime as they are at the EU level.

That being the case, one might ask why (based on the evidence from Sabre's internal documents) a key limb of the CMA's findings in Sabre/Farelogix was that Sabre had the intention to improve its merchandising solutions offer.

However, it is important not to equate the outcome of the CMA's assessment in a particular case with what the CMA needs to find as a matter of general principle. It is helpful to recall the evidential standard applicable to the CMA's functions under EA 2002, ss 35(1)(b) and 36(1)(b). ${ }^{130}$
127 e.g. PayPal/iZettle (fn 42), paras 5.5-5.6; Amazon/Deliveroo (Phase 2) (fn 60), paras 7.5-7.7.

128 e.g. Bauer Media Merger Inquiry (fn 81), para 8.4(a), referencing what appears to be the 'perceived potential competition' test at para 5.4.16 of CC2. 129 See Teva UK Limited $v$ Chiesi Farmaceutici SpA (fn 39).

130 See Sections 2.1. and 2.4. above. 
The CMA's assessment of the loss of potential competition must be founded in available factual evidence. The first stage of the CMA's analysis is therefore to ascertain that factual foundation, e.g. in the parties' internal documents.

The precise factual foundation will depend upon the available evidence and the specific context. For example, in Sabre/Farelogix when assessing the merchandising market, the CMA had evidence that Sabre intended to develop its offering in the way theorized, an apparently strong factual foundation for its theory (and the position was similar in Amazon/Deliveroo in respect of online food delivery platforms). In Bottomline/EPG, the factual foundation was the evidence that the alternative purchaser would have acquired EPG in the counterfactual. In the Bauer Media Merger Inquiry, the CMA expressly stated that it lacked evidence of Bauer's strategic intentions in the counterfactual, with Bauer's internal documents being heavily focused on its transaction strategy. ${ }^{131}$ However, whilst it only references this in its discussion of Bauer's incentives, ${ }^{132}$ it appeared that the factual foundation adopted by the CMA in that case was that it had evidence of Bauer's overall commercial strategy, which involved considering options to increase its scale. ${ }^{133}$ The CMA appeared to consider that a sufficient basis for it to proceed to its ability and incentive analysis.

Also relevant here is the question of how the firm would have attained the posited expansion of its competitive offering. A number of the decisions considered above show that the CMA has the firm view that, where an expansion of competitive offering could take place via a number of means (such as an alternative, more competitive acquisition, a partnership, or organically), it does not need to find that any one method would have been selected on a 'balance of probabilities' standard. It is sufficient that it can satisfy itself that the most likely outcome is that one of the options would have been adopted. This is consistent with the case law regarding the CMA's approach to the counterfactual as discussed at Section 2.2. above.

Whilst this limb is perhaps the least clearly articulated in the CMA's practice, it does appear to be an important one. Indeed, it is clear from the case law discussed in Section 2.1. that a factual foundation is essential at both Phase 1 and Phase 2 in UK merger control.

\section{b. Ability}

Assessing the ability of the firm to expand its competitive offering has two key limbs:
- whether there are any barriers to entry or expansion in the relevant market, and, if so, whether the firm could overcome them; and

- whether the firm would be able to compete in the market on a sustained basis.

The first limb is a gating question. The best example of this in the CMA's practice can be seen by comparing the outcomes of Amazon/Deliveroo (in respect of Amazon's potential re-entry into the supply of online food delivery platforms) and Takeaway.com/Just Eat. These were two transactions considering the same theory of harm in the same market with Phase 1 decisions separated by just four months. In Takeaway.com/Just Eat, the CMA concluded that Takeaway.com would not be able to overcome the significant barriers to entry in the UK online food delivery platforms market. However, in Amazon/Deliveroo, it found that Amazon was 'particularly well placed' to do so. ${ }^{134}$

The second limb is less prevalent as an express consideration in the CMA's recent practice. Indeed, in many cases it may not be possible to disentangle this question from the question of whether a firm can enter successfully. However, it is clear from principles espoused in the case law of the CJEU that this is an important element in the assessment of potential competition and a separate question to the issue of whether entry is possible. ${ }^{135}$ This question may also be one which seeps into the incentive limb, as part of an assessment of whether entry would be profitable.

\section{c. Incentive}

The final limb in determining whether or not a transaction has given rise to a loss of potential competition is to assess whether the relevant firm had the incentive to expand its competitive offering in the way posited.

Part of the question here is whether it would be profit maximizing for the firm to expand its competitive offering in the way posited. This requires assessing the costs of entry and the firm's likelihood of success and also weighing these factors to determine whether entry would be successful. For this reason, the question of whether a firm has the ability to compete on a sustained basis becomes a question of both ability and incentive.

This limb is however broader than that quantitative question. It also requires the CMA to link its analysis back to the factual foundation, and assess whether the posited change to the firm's competitive offering would attain the underlying strategic goal which the CMA has

134 Amazon/Deliveroo (Phase 1) (fn 59), para 206.

135 See Section 2.3. above. 
established on the available evidence (or, in cases where there is evidence of intention to achieve a particular end, whether it contributes to achieving that end).

A framework involving these three steps meets the requirements set out in both the UK and EU case law as set out in Section 2 above. It embeds the CMA's decision in factual evidence as required by the SLC test, ${ }^{136}$ whilst also focussing on the ability and incentive of the relevant firm to expand its competitive offering, as the CJEU has stated is essential when assessing potential competition. ${ }^{137}$

\section{d. Impact of the loss of potential competition}

In many cases it could be taken for granted that any potential competition between merger parties would be lost as a result their combination. However, this cannot be assumed where the transaction involves an acquisition of less than $100 \%$ of the target. In such cases, it is important to assess the impact that the acquisition will have on the parties' incentives, before concluding whether the potential competition that would have existed in the counterfactual is lost. The importance of this issue is clear from the CMA's approach at Phase 2 in Amazon/Deliveroo.

Having determined that a transaction does give rise to a loss of potential competition, the final question for the CMA to answer is what the impact of that loss of potential competition is, i.e. is it substantial such that an SLC arises? Apprising the CMA's approach is challenging based on published decisions, as the CMA's assessment, in particular as regards the contents of parties' internal documents, is often heavily redacted. Nonetheless, certain general themes can be observed.

A number of the CMA's recent decisions in this area have been in highly concentrated markets and/or markets where the CMA identified potential concerns about the effectiveness of existing competition (e.g. Amazon/Deliveroo - online food delivery platforms (at Phase 1), Sabre/Farelogix and the Bauer Media Merger Inquiry). In such cases, the CMA appears to view it sufficient to conclude that the lost chance to increase competition is sufficient to constitute an SLC.

In other cases, the CMA will proceed to assess the impact of the loss of potential competition using its conventional framework for the assessment of horizontal mergers, assuming that one or both firms (as applicable) has expanded its competitive offering in the manner posited (e.g. Amazon/Deliveroo - online convenience grocery (at Phase 1), PayPal/iZettle, Bottomline/EPG).

136 See Sections 2.1. and 2.4

137 See Sections 2.3. and 2.4.

138 See MLex, 'Comment: UK CMA's tough merger approach shows little sign of letting up', 24 June 2020, available at: https://www.mlex.com/
The toolkit used to examine this limb is reasonably well understood and articulated in the CMA's guidance. However, the CMA's approach must be reconciled with the evidential standard the case law requires in assessing the loss of potential competition. So whilst the CMA can use existing analytical tools to assess the impact of a loss of potential competition, it must ensure that it has evidence of sufficient probative quality to show an SLC on the balance of probabilities, especially in circumstances where there is little or no existing competitive relationship between the merger parties, or where the competitive impact it envisages is not likely to occur until a distant point in the future.

\section{Conclusion - the case for revised CMA guidance}

We have explained above that there appears to be a consistent methodology running through the CMA's decisional practice in the context of transactions giving rise to the loss of potential competition that is not fully reflected in its written guidance documents. By way of conclusion, set out below are four reasons why there would be value in the CMA revising CC2 to clearly articulate its approach to these cases, and give certainty to practitioners and merging parties. It is noted that the CMA may be issuing revised merger assessment guidance later this year. ${ }^{138}$

\subsection{CC2 does not adequately capture the CMA's approach}

The primary reason is that the existing guidance ${ }^{139}$ does not adequately reflect the nuances of the CMA's approach to the loss of potential competition. No reference is made to the intention, ability and incentive framework. Nor does it set out a clear explanation of the evidential focus of the CMA. Articulating this would bring much need clarity.

\subsection{Transactions giving rise to the loss of potential competition are likely to continue to be an area of focus for the CMA}

The increased intervention on the part of the CMA in cases involving the loss of potential competition appears to be partly motivated by a concern that failing to closely 
analyse the loss of potential competition in past cases has led to under-enforcement. For instance, the CMA's Chief Executive, Andrea Coscelli, described the Office of Fair Trading's ${ }^{140}$ decision to clear Facebook's acquisition of Instagram in $2012^{141}$ as 'naïve', in part because it failed to fully consider what Instagram may have grown to become in the counterfactual. ${ }^{142}$

This history, the focus this area has in the competition policy debate across Europe, ${ }^{143}$ and public pressure for the CMA to take an interventionist stance in this area, ${ }^{144}$ all operate together to suggest that this is a trend which is likely to continue. This adds to the need for the CMA's approach to be clearly articulated.

\subsection{The voluntary nature of the UK regime}

The UK regime is unique amongst European regimes, and one of the few regimes in the world in which merger filings are voluntary, not mandatory, where the thresholds are met. The CMA's Mergers Intelligence Unit actively monitors for transactions which may give rise to potential competition problems and the CMA has the power to commence investigations of its own initiative.

This means that for merging parties the question of whether or not a transaction should be notified to the CMA is not purely a jurisdictional question, but requires an assessment of the substantive merger control risk of the case so that firms can take a view on the likelihood of CMA intervention should they choose not to file. Firms and their advisers often need to reach a decision on such issues quickly, so as to fit in with the overall transaction timetable. Substantive merger control assessment is already a complex and nuanced exercise requiring careful weighing of evidence which in practice is often incomplete. Guidance which fully captures the current approach of the CMA would be of great value in supporting firms and practitioners in answering this difficult question.

Getting the 'right' answer on whether or not to voluntarily notify the CMA has taken on increased importance in the current environment given the CMA's increasingly interventionist approach to procedural infringements, including in respect of initial enforcement orders imposed on completed transactions. ${ }^{145}$ Not only do firms risk financial penalties for procedural infractions, but managing day-to-day compliance in completed mergers can require significant diversion of time and resources, both from the substantive merger review process and from the running of the firm's business.

\subsection{Difficulty in remedying cases}

A detailed discussion of CMA remedy policy is beyond the scope of this article. However, the decisions considered in Section 3 above demonstrate that the loss of potential competition can often be difficult to remedy. This can lead to the increased risk of transactions being aborted, either through prohibition or through parties abandoning deals rather than enduring a lengthy, expensive, and ultimately unsuccessful merger review process.

This issue arises because, in transactions which include issues of potential competition, such issues often encompass the entire transaction or at least cut to the very heart of it. Moreover, the nature of the theories of harm in these cases do not readily lend themselves to clear-cut remedies (e.g. if the theory of harm is predicated on a merging party otherwise entering a new market, and the absence of that entry constitutes an SLC, it can be difficult to articulate a clear-cut remedy, short of prohibition, which would be effective).

As a result Sabre/Farelogix was prohibited, after a behavioural remedy proposed by the parties was rejected. Whilst the Bauer Media Merger Inquiry was cleared subject to a behavioural remedy, the CMA was keen to emphasize that there were a number of 'very unusual' features of that case which led to that outcome. ${ }^{146}$

Merging parties and practitioners therefore need to be in a position to asses substantive merger control risk at as early a stage as possible. Clarified guidance on the CMA's approach would assist in achieving this.
140 A predecessor body to the CMA.

141 ME/5525/12 Anticipated acquisition by Facebook Inc. of Instagram Inc., decision on reference, 14 August 2012.

142 See MLex, 'Facebook, Instagram clearance may have been 'naïve,' CMA boss says', 7 September 2018, available at: https:/www.mlex.com/GlobalAntitrust/ DetailView.aspx? cid=1020888\&siteid=190\&rdir=1 (accessed 30 August 2020). This led to the CMA commissioning a report by Lear, considering the CMA's approach to merger control in digital markets (Lear, Ex-post Assessment of Merger Control Decisions in Digital Markets, Final report, 9 May 2019).

143 See Section 1.
144 See, e.g. MLex, 'Visa-Plaid deal shows 'more interventionist' merger approach needed, former payments regulator says', 19 May 2020, available at: https://www.mlex.com/GlobalAntitrust/DetailView.aspx?cid=1189250\& siteid=190\&rdir=1 (accessed 30 August 2020). On 24 August 2020, the CMA unconditionally cleared Visa's acquisition of Plaid following a Phase 1 review.

145 For a discussion see M. Jephcott and R. Allen, 'The CMA steps up enforcement of procedural merger control rules: key lessons from recent cases' (2020) 19(1) CLJ 10-23.

146 Bauer Media Merger Inquiry (fn 81), para 14.18. 